\title{
Drag Force on a Conductive Spherical Drop in a Nonuniform Magnetic Field
}

\author{
J. Walker \\ W. M. Wells
}

\section{OAK RIDGE NATIONAL LABORATORY} OPERATED BY UNION CARBIDE CORPORATION - FOR THE DEPARTMENT OF ENERGY 


\section{DISCLAIMER}

This report was prepared as an account of work sponsored by an agency of the United States Government. Neither the United States Government nor any agency Thereof, nor any of their employees, makes any warranty, express or implied, or assumes any legal liability or responsibility for the accuracy, completeness, or usefulness of any information, apparatus, product, or process disclosed, or represents that its use would not infringe privately owned rights. Reference herein to any specific commercial product, process, or service by trade name, trademark, manufacturer, or otherwise does not necessarily constitute or imply its endorsement, recommendation, or favoring by the United States Government or any agency thereof. The views and opinions of authors expressed herein do not necessarily state or reflect those of the United States Government or any agency thereof. 


\section{DISCLAIMER}

Portions of this document may be illegible in electronic image products. Images are produced from the best available original document. 


\section{Printed in the United States of America. Available from}

Natıonal Technical Information Service

U.S. Department of Commerce

5285 Port Royal Road, Springfield, Virginia 22161

NTIS price codes-Printed Copy: A03; Microfiche A01

This report was prepared as an account of work sponsored by an agency of the United States Government. Neither the United States nor any agency thereof, nor any of their employees, makes any warranty, expressed or implied, or assumes any legal liability or responsibility for any third party's use or the results of such use of any information, apparatus, product or process disclosed in this report, or represents that its use by such third party would not infringe privately owned rights. 
Contract No. W-7405-eng-26

\section{FUSION ENERGY DIVISION}

DRAG FORCE ON A CONDUCTIVE SPHERICAL DROP IN A NONUNIFORM MAGNETIC FIELD

\section{J. Walker}

W. M. Wells

\section{September 1979}

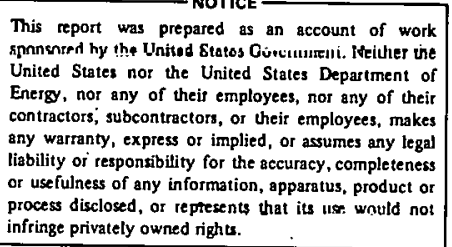

Prepared by the

OAK RIDGE NATIONAL LABORATORY

Oak Ridge, Tennessee 37830

operated by

UNION CARBIDE CORPORATION

for the

DEYARTMENT OF ENERGY 
THIS PAGE

\section{WAS INTENTIONALLY LEFT BLANK}




\section{CONTENTS}

ABSTRACT $\ldots \ldots \ldots \ldots \ldots \ldots \ldots \ldots \ldots \ldots \ldots \ldots \ldots \ldots \ldots \ldots \ldots \ldots \ldots \ldots \ldots$

INTRODUCTION $\ldots \ldots \ldots \ldots \ldots \ldots \ldots \ldots \ldots \ldots \ldots \ldots \ldots \ldots \ldots \ldots \ldots \ldots \ldots$

1. GEOMETRY, ASSUMPTIONS, AND GOVERNING EQUATIONS $\ldots \ldots \ldots \ldots \ldots \ldots \ldots$

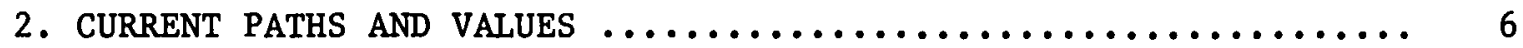

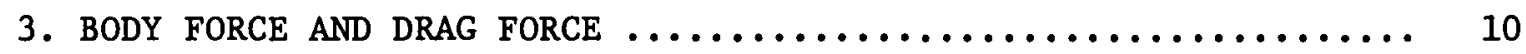

4. PRESSURE AND DROP DEFORMATION $\ldots \ldots \ldots \ldots \ldots \ldots \ldots \ldots \ldots \ldots \ldots \ldots$

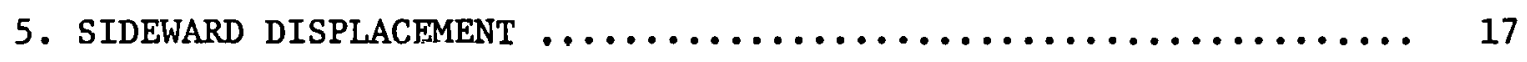

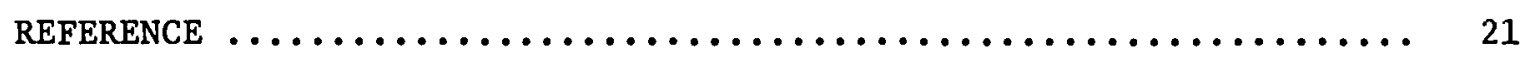




\section{THIS PAGE}

\section{WAS INTENTIONALLY}

LEFT BLANK 
A high velocity lithium droplet cloud traversing the magnetic field of a fusion reactor may be useful for collecting plasma ions and their energy. In this report, the forces associated with such motion in nonuniform magnetic fields are derived. 


\section{INTRODUCTION}

Fusion reactors may require magnetic divertors to carry off plasma impurities. A magnetic divertor consists of conductors properly arrayed to distort flux lines in the edge of the plasma into a configuration where they are more or less removed from the plasma region. This edge plasma will follow the diverted flux and can, in principle, be collected. This provides a mechanism to prevent impurities from the wall from reaching the bulk of the plasma and also to divert impurities away from the wall as they leave the plasma.

Collection of both the incident ions and the associated heat flux promises to be a technological challenge. In the former case, the ion collection load is estimated to be of the order of $10^{23} / \mathrm{sec}$ and the attendant surface heat $f 1 u x$ is expected to be in excess of $100 \mathrm{MW}$. The particle collection load is largely $D$ and $T$ 1ons. Proposals for accomplishing these tasks have involved the use of solid hydride formers and the use of liquid lithium, also a hydride former. In the case of the solid, the feasibility of the requisite number of load-unload cycles $\left(\sim 10^{5}\right)$ while maintaining good structural and heat transfer properties is doubtful. Also, the process for ion removal may involve excessive frequency and temperatures.

Proposals for the use of liquid lithium have entailed gravitydriven flow in strong magnetic fleld and also in contact with a solid metal boundary. This situation leads to excessive resistance to flow and to insufficient velocity. This is because of magnetohydrodynamic (MHD) effects associated with current that flows through the stationary return path.

It has been proposed ${ }^{1}$ that droplets of lithium formed from high velocity jets be utilized to accomplish these two functions. The jets would be formed by nozzles away from the large magnetic fields. In a short distance the jets are expected to break up. The drops would traverse the strong magnetlc field region and then be collected in a region removed from the magnetic field. The essential difference compared with the earlier proposals is that moving, electrically conductive liquid is not in contact with a stationary current return path while traversing the strong magnetic field. 
This report presents the theory to treat the motion of droplets making this journey. The first author derived the theory and the second author provided the context for this work. 
1. GEOMETRY, ASSUMPTIONS, AND GOVERNING EQUATIONS

The spherical drop of liquid metal has a radius a and is moving in the $z$ direction with velocity $V$, as indicated in Fig. 1 . The coordinate system is fixed in space, and the center of the sphere is located at the origin of the coordinate system at the instant of analysis. There is a transverse magnetic field in the $y$ direction which varies in strength in the $z$ direction, $B_{\dot{y}}(z)$. We can write a Taylor series for this field about $z=0$,

$B_{y}(z)=B_{y}(0)+z \frac{\partial B}{\partial z}(0)+\frac{1}{2} z^{2} \frac{\partial^{2} B}{\partial z^{2}}(0)+\ldots \cdot \cdot$

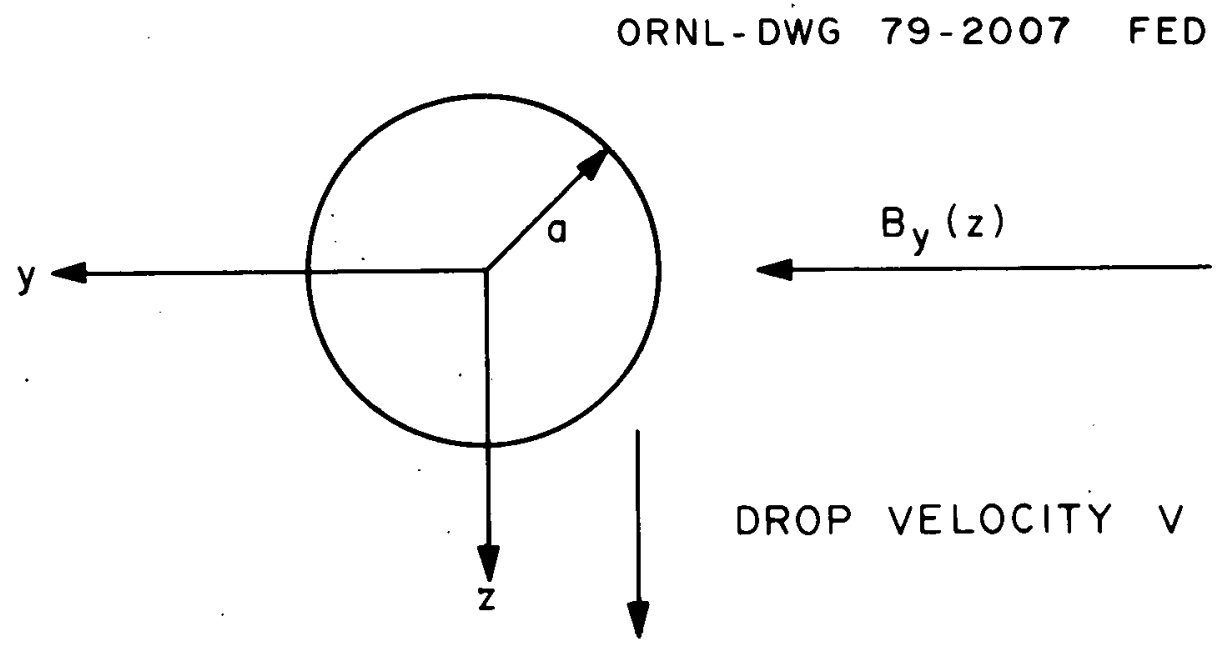

Fig. 1. Spherical drop of liquid metal.

If the distance over which the magnetic field strength changes is much larger than the radius of the spherical drop, then

$\mathrm{B}_{\mathrm{y}}(0) \gg \mathrm{a} \frac{\partial \mathrm{B}}{\partial \mathrm{z}}(0) \gg \frac{1}{2} \mathrm{a}^{2} \frac{\partial^{2} \mathrm{~B} y}{\partial \mathrm{z}^{2}}(0) \ldots .$.

We therefore retain only the first two terms in this Taylor series, 
$B_{y}(z)=B_{0}+z \frac{\partial B_{0}}{\partial z}$,

where $B_{0}=B_{y}(0) ; \partial B_{0} / \partial z=\partial B_{y} / \partial z(0)$, and the second term is much smaller than the first.

The governing equations for incompressible fluid are

$$
\begin{aligned}
& \rho\left[\frac{\partial \underset{m}{\partial t}}{\partial t}(\underset{m}{V} \cdot \underset{m}{\nabla}) \underset{m}{V}\right]=-\underset{m}{\nabla p}+j \times \underset{m}{B}+\eta \nabla^{2} V_{m}^{V}, \\
& \underset{m}{\nabla .} \cdot \underset{m}{V}=0, \\
& \underset{m}{\nabla} \cdot \underset{m}{j}=0, \\
& \underset{m}{j}=\underset{i}{\sigma}(-\underset{m}{\nabla} \phi+\underset{m}{V} \times \underset{m}{B}),
\end{aligned}
$$

where $\mathrm{m}_{\mathrm{m}}, \mathrm{p}, \underset{\mathrm{m}}{\mathrm{j}}, \underset{\mathrm{m}}{\mathrm{B}}$, and $\phi$ are the fluid velocity, pressure, electric current density, magnetic field, and electric potential, respectively, and $\rho, \eta$, and $\sigma$ are the fluid's density, viscosity, and electrical conductivity, respectively. These equations assume that the magnetic Reynolds number $R_{m}=\mu \sigma V a \ll 1$, where $\mu$ is the fluid's magnetic permeability, and that the magnetic field is steady, rather than a function of time.

We write

$\mathrm{V}_{m}=\mathrm{Vk}_{m}+\mathrm{V}_{m}^{\prime}$

where $V$ is the drop velocity, which is the same at every point in the drop, and $\hat{\mathrm{k}}$ is a unit vector in the $z$ direction. The body forces obtained under the assumption that the drop moves as a rigid body, i.e., $y^{\prime} \equiv 0$, cannot in fact be balanced entirely by a pressure gradient. Therefore, there must be some internal motion relative to the rigid body motion. However, we will show that the velocity in this relative motion is comparable to the change in drop velocity resulting from the drag force on the drop, and this is much smaller than the initial drop velocity. 
Therefore we assume that $\left|V_{m}^{\prime}\right| \ll V$ and neglect $V_{m}^{\prime}$, and we also assume that $\partial \mathrm{V} / \partial t$ is negligible. Therefore $\mathrm{Eq}$. (1a) becomes

$\underset{m}{\nabla p}=\underset{m}{j} \times \underset{m}{B}$ 


\section{CURRENT PATHS AND VALUES}

To describe current paths, we recognize that $\underset{m}{B}=B_{0} \hat{j}$, much smaller terms being neglected, where $\hat{j}_{m}$ is a unit vector in the y direction. Introducing this into Eq. (2) and taking the curl of this equation gives

$B_{0} \frac{\partial j}{\partial y}=0$

because $\underset{m}{\nabla} \times \underset{m p}{\nabla p}=0, \underset{m}{\nabla} \times(\underset{m}{j} \times \underset{m}{j})=(\partial \underset{m}{j} / \partial y)-\left(\nabla_{m} \cdot \underset{m}{j}\right)_{m}^{j}$, and $\underset{m}{\nabla} \cdot \underset{m}{j}=0$. Consider a cylindrical coordinate system $(r, \theta, y)$ with base vectors $\hat{e}_{m}$, $\hat{e}_{\theta}$, and $\hat{e}_{m y}$, as illustrated in Fig. 2. Note that $\hat{e}_{m i y}=\hat{j}_{m}$. The "top" and "bottom" surfaces of the drop as seen by the magnetic field are given by

$y= \pm\left(a^{2}-r^{2}\right)^{1 / 2}$

ORNL-DWG 79-2008 FED

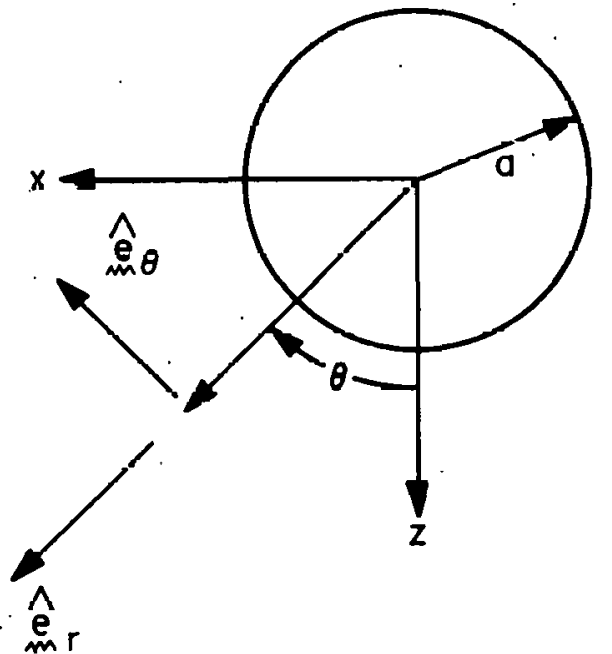

$\mathrm{B}_{\mathrm{O}}$

\& $y$-AXIS AND MAGNETIC FIELD POINT INTO THE PLANE.

Fig. 2. Cylindrical coordinate system for describing current paths.

Because the surrounding vacuum carries no electric current, the boundary condition on the electric current in the liquid is

$j_{m}^{j} \cdot \underset{m}{\hat{n}}=0$ 
at the surface, where $\hat{\mathrm{n}}$ is an outward unit normal on the surface. The unit normal can be found with the following procedure. A scalar function is defined by

$F(r, \theta, y)= \pm y-\left(a^{2}-r^{2}\right)^{i / 2}$

This function equals zero on the drop surface, so this surface is a surface of constant value for this function. The gradient of any scalar function is perpendicular to the function's constant value surfaces, so

$\underset{m}{\nabla F}=r\left(a^{2}-r^{2}\right)-1 / 2 \hat{m}_{m} \pm \hat{e}_{m y}$

Is perpendicular to the drop surface. Normalizing to get unit length, we obtain

$\hat{\underline{n}}=a^{-1} \hat{\underline{m}}_{\underline{r}} \pm a^{-1}\left(a^{2}-r^{2}\right)^{1 / 2} \hat{\underline{e}}_{y}$ at $y= \pm\left(a^{2}-r^{2}\right)^{1 / 2}$.

The boundary condition on the electric current is

$a^{-1} r j_{r} \pm a^{-1}\left(a^{2}-r^{2}\right)^{1 / 2} j_{y}=0$ at $y= \pm\left(a^{2}-r^{2}\right)^{1 / 2}$

Since $\partial j_{m} / \partial y=0, j_{r}, j_{\theta}$, and $j_{y}$ are functions of $r$ and $\theta$ alone, so the boundary conditions become

$$
\begin{aligned}
& a^{-1} r j_{r}(r, \theta)+a^{-1}\left(a^{2}-r^{2}\right)^{1 / 2} j_{y}(r, \theta)=0, \\
& a^{-1} r j_{r}(r, \theta)-a^{-1}\left(a^{2}-r^{2}\right)^{1 / 2} j_{y}(r, \theta)=0 .
\end{aligned}
$$

When these equations are added, they give $j_{r}(r, \theta)=0$, and when they are subtracted, they give $j_{y}(r, \theta)=0$. Therefore, $j_{\theta}(r, \theta)$ is the only nonzero current. Equation (1c) becomes $\partial j_{\theta} / \partial \theta=0$, so $j_{\theta}$ is a function of $r$ alone and $j_{m}=j_{\theta}(r) \hat{e}_{\theta}$. 
By ignoring the nonuniformity in the magnetic field, we have come to the conclusion that the electric current flows around cylinders which are concentric with the diameter parallel to the magnetic field, and that the current on one of these cylinders is constant, as illustrated in Fig. 3(a). If we were to include the nonuniformity of the field, the effect would be to distort the cylinders slightly. Where the field strength is stronger, the characteristic surface must be longer and parallel to $\mathrm{B}$, and vice versa. Thus, if $\underset{\mathrm{m}}{\mathrm{B}}$ is increasing in the $z$ direction, the surface might look like the diagram in Fig. 3(b). Note that the total current flowing around a surface is constant, so that where the magnetic field is strong and the surface is long, the current density will be small, and where the field is weak and the surface is short, the current density will be large. Because the body force is equal to the product of current density and field strength, and because where the field is large the current is small and vice versa, the forces are somewhat insensitive to nonuniform field effects. Because $a \partial B_{0} / \partial z \ll B_{0}$, all nonuniform field effects on the shape of the characteristic surfaces and on variation of current density around these surfaces will be neglected.

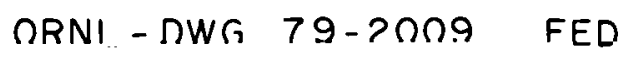

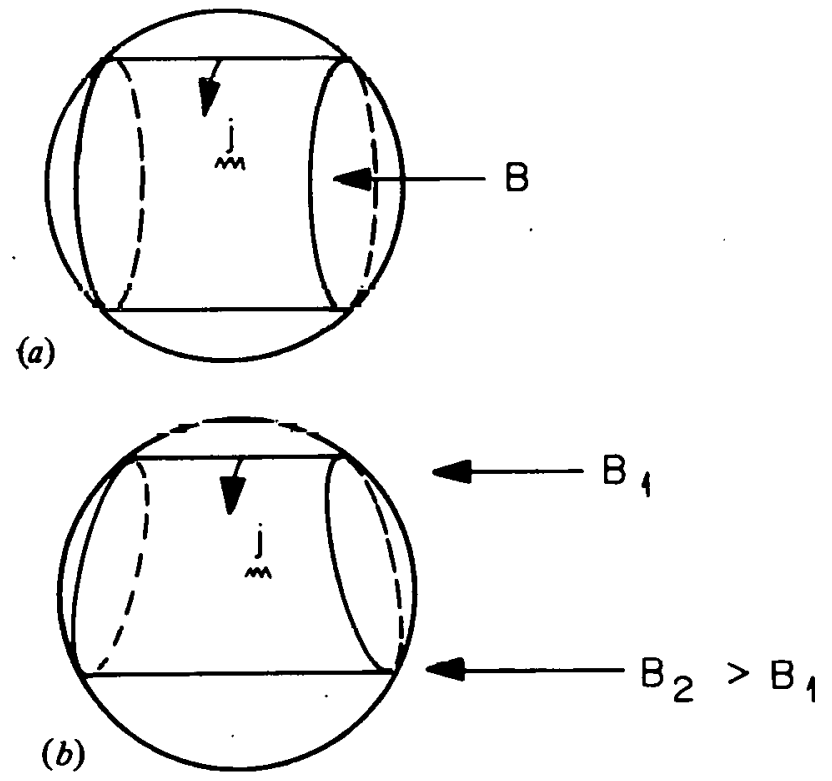

Fig. 3. Pattern of electric flow current (a) without and (b) with nonuniformity of field. 
To compute the value of $j_{\theta}(r)$ on one of the cylinders of radius $r$ (see Fig. 4), we consider the $\theta$ component of Ohm's law, Eq. (1d). The velocity of the fluid is the drop velocity, so that $V_{m}=V \hat{k}$, where $V$ is a constant; $\underset{m}{\hat{k}}=\cos \hat{\theta}_{m}-\sin \hat{e}_{m \theta} ;$ and ${\underset{m}{m}}_{m}=V \cos \hat{\theta}_{m r}-V \sin \theta \hat{e}_{m}$. The magnetic field is in the $y$ direction, so that

$\underset{m}{B}=\left(B_{0}+z \frac{\partial B_{0}}{\partial z}\right) \underset{m}{\hat{j}}=\left(B_{0}+r \cos \theta \frac{\partial B_{0}}{\partial z}\right) \underset{m y}{\hat{e}_{y}}$,

because $z=r \cos \theta$ and $\hat{j}=\hat{e}_{y}$. Therefore the $\theta$ component of Eq. (Id) is $j_{\theta}(r)=-\sigma\left[r^{-1} \frac{\partial \phi}{\partial \theta}+v \cos \theta\left(B_{0}+r \cos \theta \frac{\partial B_{0}}{\partial z}\right).\right]$.

When this equation is integrated from $\theta=0$ to $\theta=2 \pi$ and the result is divided by $2 \pi$, it gives

$j_{\theta}(r)=-\frac{1}{2} \sigma \operatorname{Vr} \frac{\partial B_{0}}{\partial z}$,

because $\phi(\theta=0)=\phi(\theta=2 \pi)$.

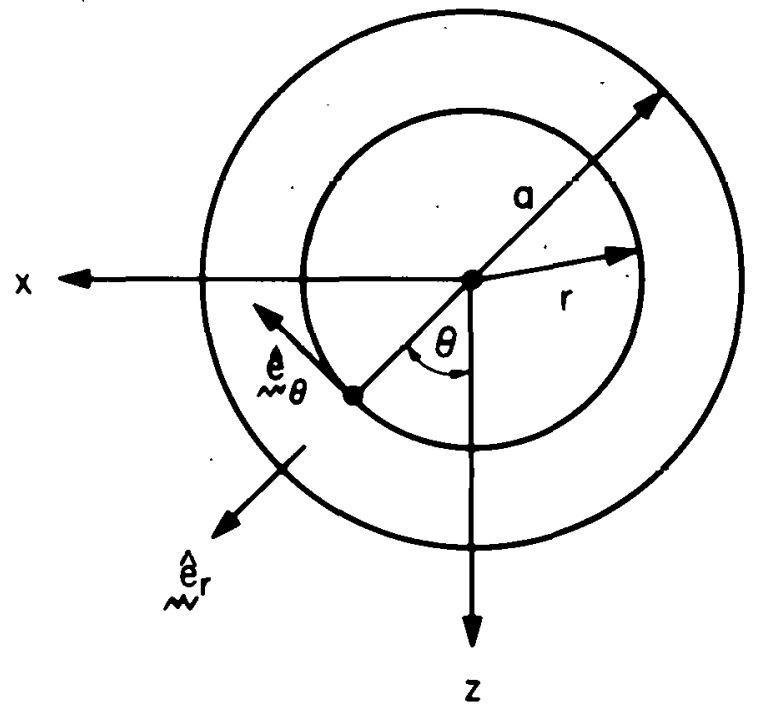

ORNL-DWG 79-2010 FED

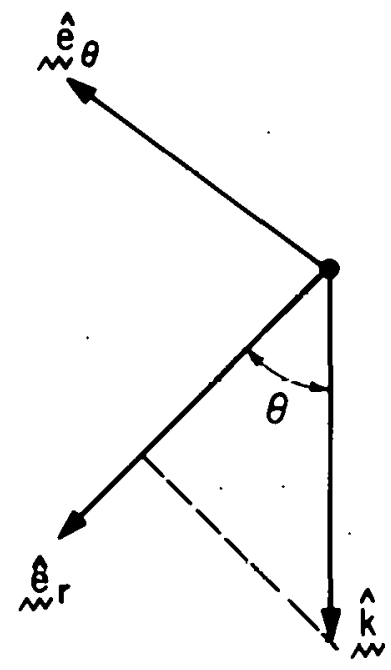

Fig. 4. Model for computing $j_{\theta}(r)$. 
The Lorentz body force per unit volume is

$$
\begin{aligned}
\underset{m}{f} & =\underset{m}{j} \times \underset{m}{B}=-\frac{1}{2} \sigma V r \frac{\partial B_{0}}{\partial z} \hat{e}_{\dot{m}} \times\left(B_{0}+r \cos \theta \frac{\partial B_{0}}{\partial z}\right) \hat{e}_{y} \\
& =-\frac{1}{2} \sigma \operatorname{Vr} \frac{\partial B_{0}}{\partial z}\left(B_{0}+r \cos \theta \frac{\partial B_{0}}{\partial z}\right) \hat{m}_{m} .
\end{aligned}
$$

This is illustrated in Fig. 5. First we are interested in the net force on the drop in the $z$ direction because this is the drag force on the drop due to IHD effects. We calculate

$d F_{z}=\underset{m}{f} \cdot \underset{m}{\hat{k}} \cdot d \forall$,

where $\hat{k}=\cos \theta \hat{e}_{m}-\sin \theta \hat{e}_{m}$ and $\mid d \psi=d r(r d \theta) d y$. To integrate over the entire drop, we integrate from $\theta=0$ to $\theta=2 \pi$, from $y=-\left(a^{2}-\right.$ $\left.r^{2}\right)^{1 / 2}$ to $y=\left(a^{2}-r^{2}\right)^{1 / 2}$, and from $r=0$ to $r=a$, so that

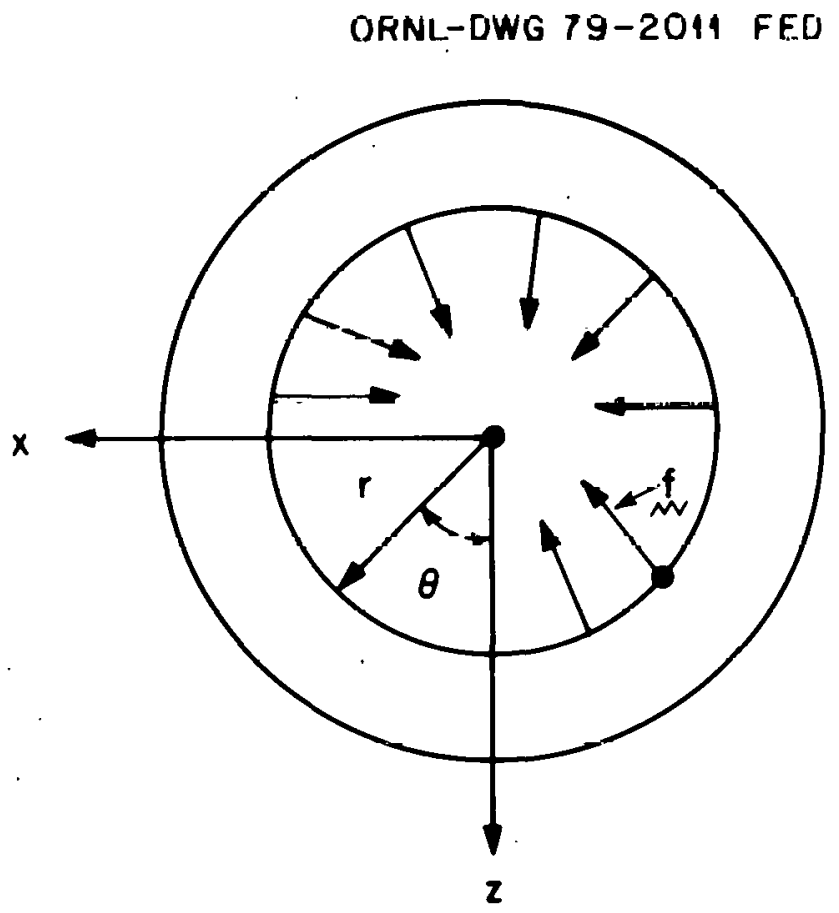

Fig. 5. Lorentz body force per unit volume. 


$$
\begin{array}{r}
F_{z}=\int_{0}^{a} \int_{-\left(a^{2}-r^{2}\right)^{1 / 2}}^{\left(a^{2}-r^{2}\right)^{1 / 2}} \int_{0}^{2 \pi}\left[-\frac{1}{2} \sigma V r \frac{\partial B_{0}}{\partial z}\left(B_{0}+r \cos \theta \frac{\partial B_{0}}{\partial z}\right)\right] \\
\times \cos \theta r d \theta d y d r .
\end{array}
$$

If the integrations with respect to $y$ and $\theta$ are carried out, the result is

$$
F_{z}=-\pi \sigma V\left(\frac{\partial B_{0}}{\partial z}\right)^{2} \int_{0}^{a}\left(a^{2}-r^{2}\right)^{1 / 2} r^{3} d r
$$

The result of integrating is

$$
F_{z}=-\frac{2}{15} \pi a^{5} \sigma V\left(\frac{\partial B_{0}}{\partial z}\right)^{2}
$$

Because the field gradlent appears squared, the force is opposed to the motion whether the field is increasing or decreasing in the direction of the motion. The magnetic field strength is given by a graph like the one in Fig. 6. It seems reasonable to assume that $\mathrm{B}_{\mathrm{y}}$ is given by

$$
B_{y}=\frac{1}{2} B_{u}[1-\cos (\pi z / L)]
$$

ORNL DWG 792012 FED

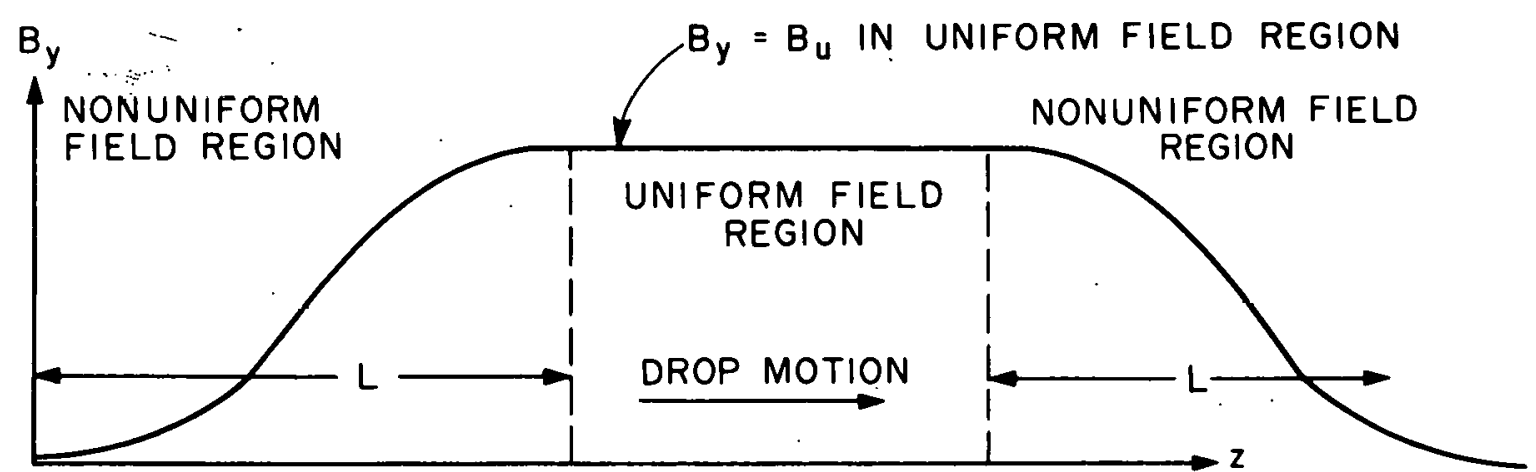

MAGNETIC FIELD STRENGTH

Fig. 6. Magnetic field strength. 
for $0 \leqslant z \leqslant L$, so that

$\frac{\partial B_{y}}{\partial z}=\frac{\pi B_{u}}{2 L} \sin (\pi z / L)$

Because $\mathrm{F}_{z}=\mathrm{m} d \mathrm{~V} / \mathrm{dt}$, where $\mathrm{m}=(4 / 3) \pi \mathrm{a}^{3} \rho$ is the mass of the drop, and because $\mathrm{V}=\mathrm{dz} / \mathrm{dt}$, we have

$\frac{F_{2}}{V}=-\frac{2}{15} \pi a^{5} \sigma\left(\frac{\partial B_{0}}{\partial z}\right)^{2}=\frac{4}{3} \pi a^{3} \rho \frac{d V / d t}{d z / d t}$

or

$\frac{\mathrm{dV}}{\mathrm{dz}}=-\frac{\sigma \mathrm{a}^{2}}{10 \rho}\left(\frac{\partial \mathrm{B}_{0}}{\partial \mathrm{z}}\right)^{2}$

Introducing the expression assumed for the field gradient where the drop enters the field, we ublalu all expression for the changc in drop volocity during the entry,

$\Delta V=-\frac{\sigma a^{2}}{10 \rho}\left(\frac{\pi B_{u}}{2 L}\right)^{2} \int_{0}^{L} \sin ^{2}(\pi z / L) d z$

or

$\Delta V=-\pi^{2} a^{2} \sigma B_{u}^{2} / 80 \rho L$

This is the change in the drop's velocity during its motion from outside the magnetic field to the region of uniform magnetic field. An equal decrease in velocity results during the drop's motion from the uniform field region to a point outside the field, so that the total change in velocity of a drop moving across the field region is

$\Delta V=-\pi^{2} a^{2} \sigma B_{u}^{2} / 40 \rho L$ 


\section{PRESSURE AND DROP DEFORMATION}

Equation (2), together with the result for the Lorentz body force, gives

$\frac{\partial p}{\partial r}=-\frac{1}{2} \sigma V r \frac{\partial B_{0}}{\partial z}\left(B_{0}+r \cos \theta, \frac{\partial B_{0}}{\partial z}\right)$.

The second term in the parentheses is much smaller than the first, and we will neglect it. We should note, however, that it is the second term that accounts for the drag force, because the first produces a symmetric force fleld with no net resultant. Therefore we are neglecting forces comparable to the drag force $F_{z}$ when we neglect this term. The neglected term implies that $\mathrm{p}$ depends on $\theta$, but because the electromagnetic or Lorentz body force is radial, it cannot balance the pressure force $\mathrm{r}^{-1} \partial \mathrm{p} / \partial \theta$, and $\mathrm{Eq}$. (1a) implies that $\mathrm{V}$ is not equal to the constant value of the drop's velocity. However, this unbalanced pressure force is also comparable to the drag force, and the deviations from the rigid body velocity are comparable to the $\Delta V$ just computed. If the change in the drop's velocity due to entering and leaving the field, namely $\Delta V$, is much smaller than the drop's velocity $V$, then the motion in the drop relative to the drop's velocity, namely $\mathrm{v}^{\prime}$ ', is also much smaller than the drop's velocity $V$. This justifies the assumption (made in Sect. 1) that $\left|\mathrm{V}_{m}^{\prime}\right| \ll v$.

Neglecting the second term inside the parentheses, we integrate the equation to obtain the pressure,

$\mathrm{p}=\mathrm{p}_{0}-\frac{1}{4} \sigma \mathrm{Vr}^{2} \mathrm{~B}_{0} \frac{\partial \mathrm{B}_{0}}{\partial z}$

where $\mathrm{p}_{0}$ is the (unknown) pressure at $r=0$.

In the absence of any MHD effects, i.e., outside the field or in the uniform field region, the pressure in the drop is constant. If $s$ is the surface tension force per unit length, then $\pi a^{2} p_{s}=2 \pi a s$, or $p_{s}=$ 
2s/a, as shown schematically in Fig. 7(a). With MHD effects present, the pressure is a function of radial distance from the diameter parallel to the field, as shown in Fig. $7(\mathrm{~b})$. In the figure we introduce the term $\mathrm{p}_{1}[=\mathrm{p}(\mathrm{r}=\mathrm{a})]$. Then $\mathrm{p}_{1}>\mathrm{p}_{0}$ for $\left(\partial \mathrm{B}_{0} / \partial \mathrm{z}\right)<0$ and $\mathrm{p}_{1}<\mathrm{p}_{0}$ for $\left(\partial \mathrm{B}_{0} / \partial z\right)>0$. Because locally the pressure is related to the surface tension through the surface curvature, $r_{c} p \sim s$ or $r_{c} \sim s / p$. This relationship is shown in Fig. 8. Where the pressure is larger, the radius of curvature is smaller, and vice versa. For $\left(\partial B_{0} / \partial z\right)>0, p_{1}<p_{0}$, and for $\left(\partial B_{0} / \partial z\right)<0, p_{1}>p_{0}$. The resulting deformations for these cases are shown in Fig. 9. Because it is the difference in pressure which causes the deformation, a coefficient to estimate the deformation is the

\section{ORNL-DWG 79-2013 FED}

(a)

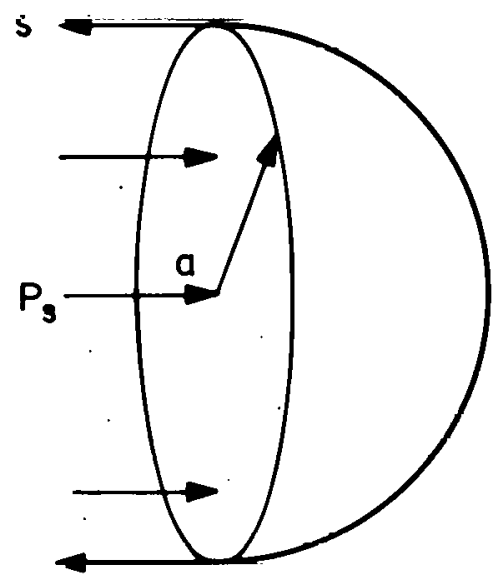

(b)

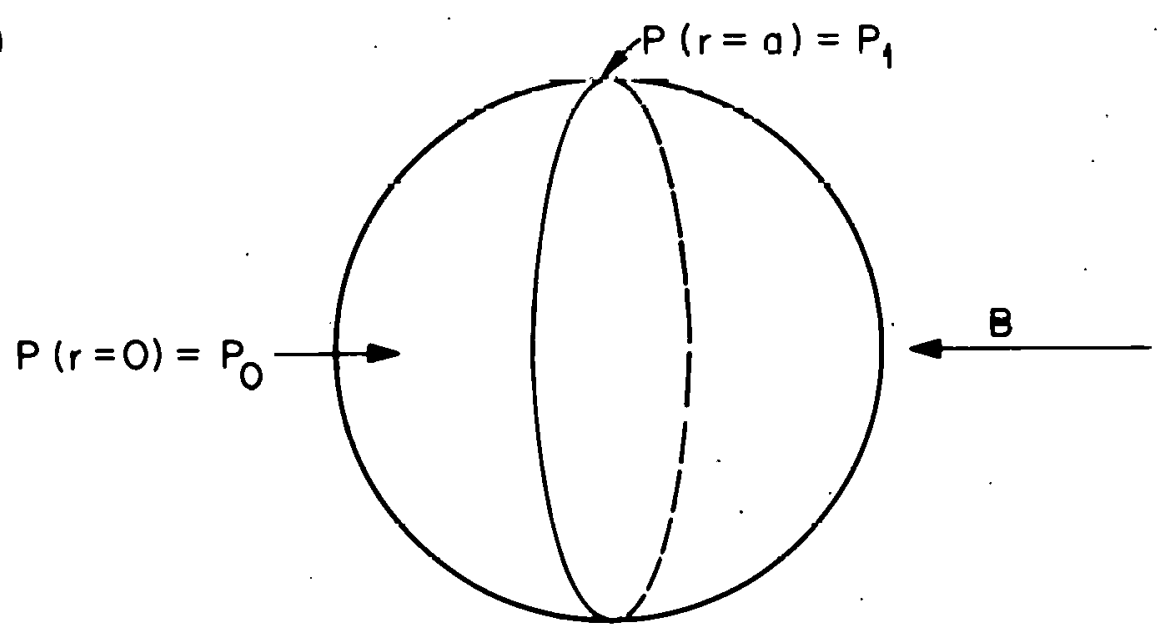

Fig. 7. (a) Constant pressure in the drop, no MHD effects present. (b) Pressure as a function of radial distance from the diameter parallel to the field, MHD effects present. 


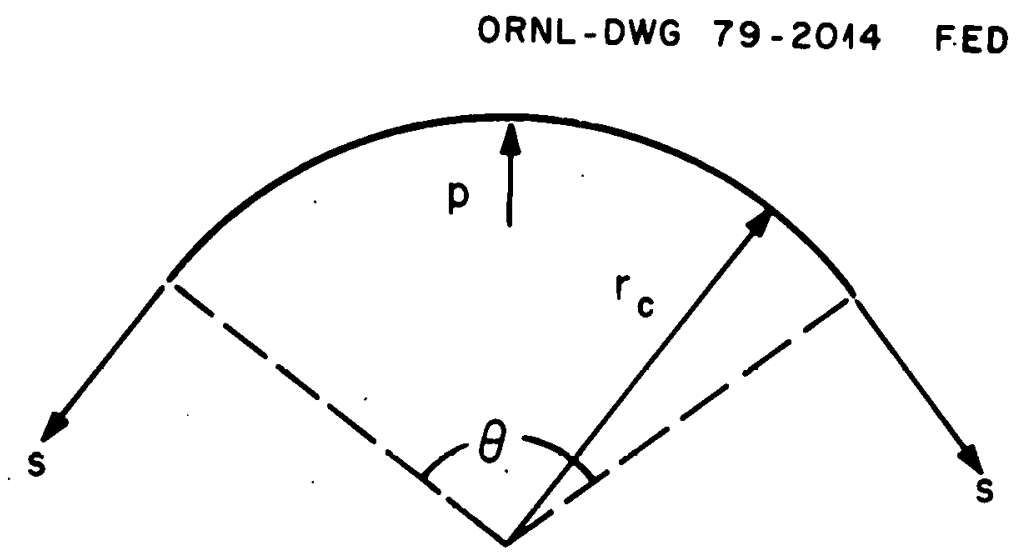

Fig. 8. Relation of pressure to surface tension.

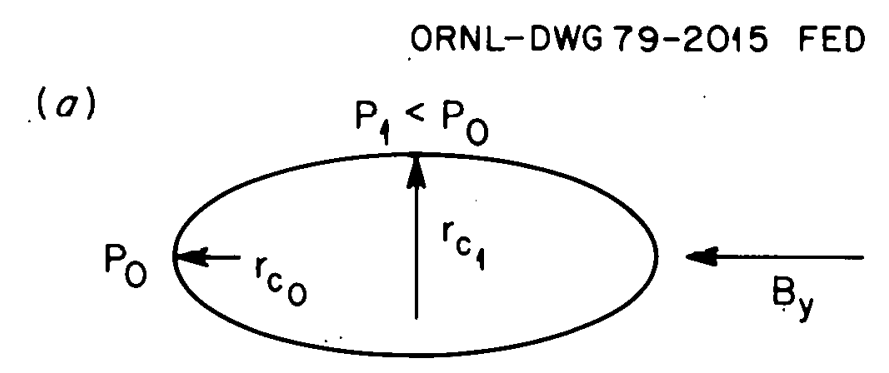

(b)

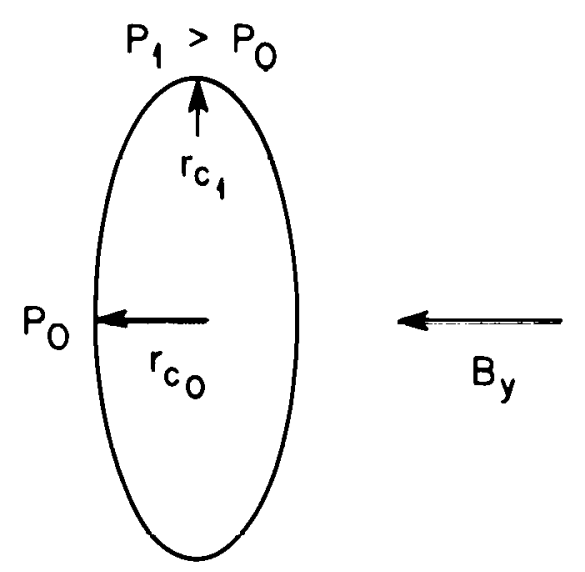

Fig. 9. Deformation of the drop (a) when $\mathrm{p}_{1}<\mathrm{p}_{0}$ and (b) when $\mathrm{P}_{1}>\mathrm{p}_{0} \cdot$ 
ratio of the maximum pressure difference inside the drop, neglecting the deformation, to the pressure in a drop due to surface tension alone. That is,

$\Delta p=p(r=0)-p(r=a)=\frac{1}{4} \sigma V^{2} B_{0} \frac{\partial B_{0}}{\partial z}$,

so

$\frac{\Delta \mathrm{p}}{\mathrm{p}_{\mathrm{s}}}=\frac{\mathrm{a}^{3}}{8 \mathrm{~s}} \sigma \mathrm{VB}_{0} \frac{\partial \mathrm{B}_{0}}{\partial \mathrm{z}}$.

This is a dimensionless coefficient that should reflect the degree of drop deformation. It should be much less than 1 to indicate negligible drop deformation. 


\section{SIDEWARD DISPLACEMENT}

A nonuniform magnetic field always implies curvature to the field lines. We can see this from Ampère's law, which for $R_{m} \ll 1$ is

$\underset{m}{\nabla} \times \underset{m}{B}=0$

For $\underset{m}{B}=B_{y}(y, z) \hat{\jmath}_{m}+B_{z}(y, z) \hat{k}_{m}$, i.e., a plane magnetic field with no $x$ component and no $x$ dependence, this equation becomes

$\frac{\partial B_{z}}{\partial y}=\frac{\partial B_{y}}{\partial z}$

Because $\partial \mathrm{B}_{\mathrm{y}} / \partial \mathrm{z} \neq 0, \mathrm{~B}_{\mathrm{z}} \neq 0$. The field line curvature is illustrated in F1g. 10. The effect of the magnetic field line curvature can be seen in Fig. 11. The characteristic surfaces tilt with the field lines, and the force previously computed as $F_{2}$ acts perpendicular to the characteristic surfaces and field lines. This force has a component perpendi-

ORNL-DWG $79-2016$

FED

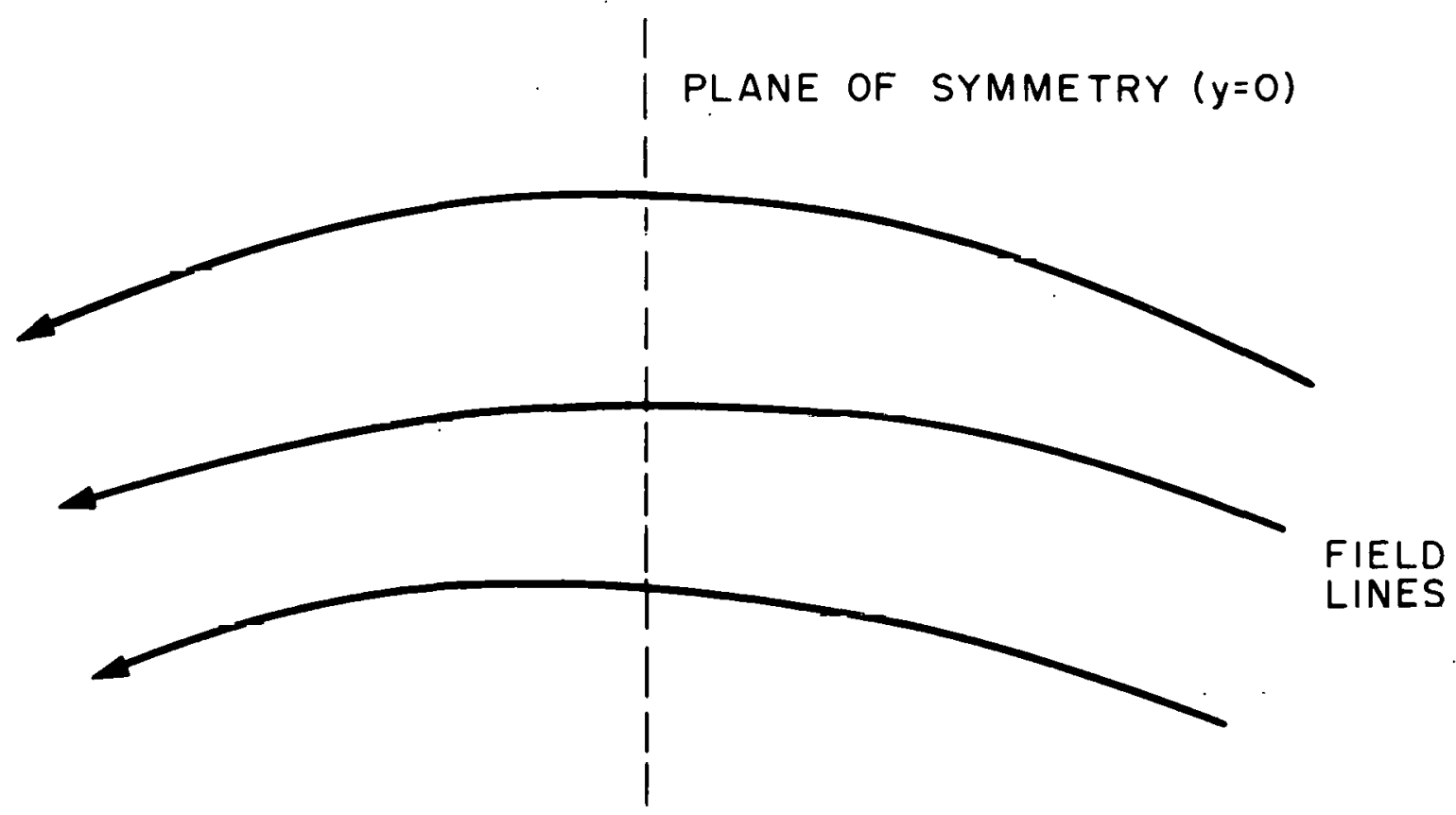

Fig. 10. Field line curvature. 
ORNL-DWG $79-2017$ FED

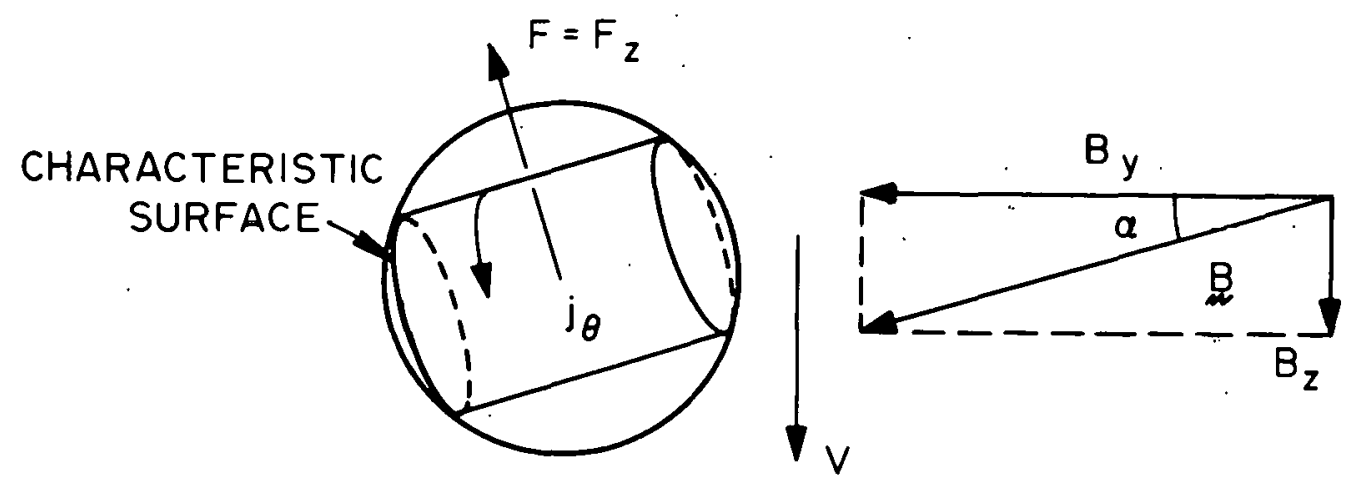

Fig. 11. Effect of field line curvature on a drop.

cular to the velocity as well as parallei to it. If $F_{z_{0}}$ is the $F_{z}$ computed before for $B_{B}=0$, then

$\mathrm{F}_{\mathrm{z}}=\mathrm{F}_{\mathrm{z}_{0}} \cos \alpha \approx \mathrm{F}_{\mathrm{z}_{0}}$

$\mathrm{F}_{\mathrm{y}}=\mathrm{F}_{\mathrm{z}_{0}} \sin \alpha \approx \mathrm{F}_{\mathrm{z}_{0}} \tan \alpha \approx \mathrm{F}_{\mathrm{z}_{0}}\left(\mathrm{~B}_{\mathrm{z}} / \mathrm{B}_{\mathrm{y}}\right)$

assuming that $\alpha$ is smal1.

Since $B_{z}=0$ at the plane of eymmetry, taken here as the $y=0$ plane, we can determine $B_{z}$ from

$B_{z}(y, z)=\int_{0}^{y} \frac{\partial B}{\partial z}\left(y^{*}, z\right) d y^{*}$.

In the drop blanket of thickness $T$ shown in Fig. 12, the largest effect will be felt by the drop at the edge of the drop blanket. If we note that $\partial \mathrm{B}_{\mathrm{y}} / \partial z$ is the same as $\partial \mathrm{B}_{0} / \partial z$, then we can estimate $B_{z}$ at the edge of the hlanket as

$B_{z}=\frac{1}{2} T \frac{\partial B_{0}}{\partial z}$ 
ORNL-DWG $79-2018$ FED

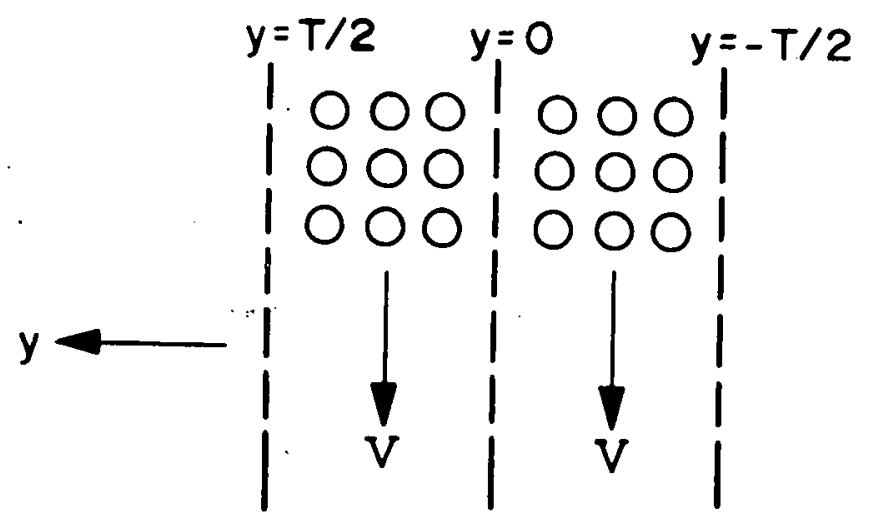

Fig. 12. Drop blanket of thickness T.

As a typical $B_{y}$, we choose $B_{u} / 2$, where $B_{u}$ is the field strength in the uniform field region. Therefore,

$F_{y}=F_{z_{0}} T \frac{\partial B_{0}}{\partial z} / B_{u}=m \frac{d^{2} y}{d t^{2}}$

Integration gives

$\Delta y=\tau^{2} F_{z_{0}} T \frac{\partial B_{0}}{\partial z} / 2 m B_{u}$,

where $\Delta y$ is the displacement of a drop at the edge of the blanket away from the other drops and $\tau$ is the time spent in the nonuniform field region. Because

$\tau=\mathrm{L} / \mathrm{V}$,

where $L$ is the length of the nonuniform field region, as before, and expressions for $\mathrm{m}$ and $\mathrm{F}_{z_{0}}$ have been given, we obtain

$\Delta y=a^{2} L^{2} \mathrm{~T} \sigma\left(\frac{\partial B_{0}}{\partial z}\right)^{3} / 20 \rho \mathrm{VB}_{\mathrm{u}}$ 
As a drop enters the magnetic field, it will move away from the plane of symmetry by this displacement, and as it leaves the magnetic field, it returns to its original distance from the plane of symetry. This is shown schematically in Fig. 13.

ORNL-DWG $79-2019 \quad$ FED

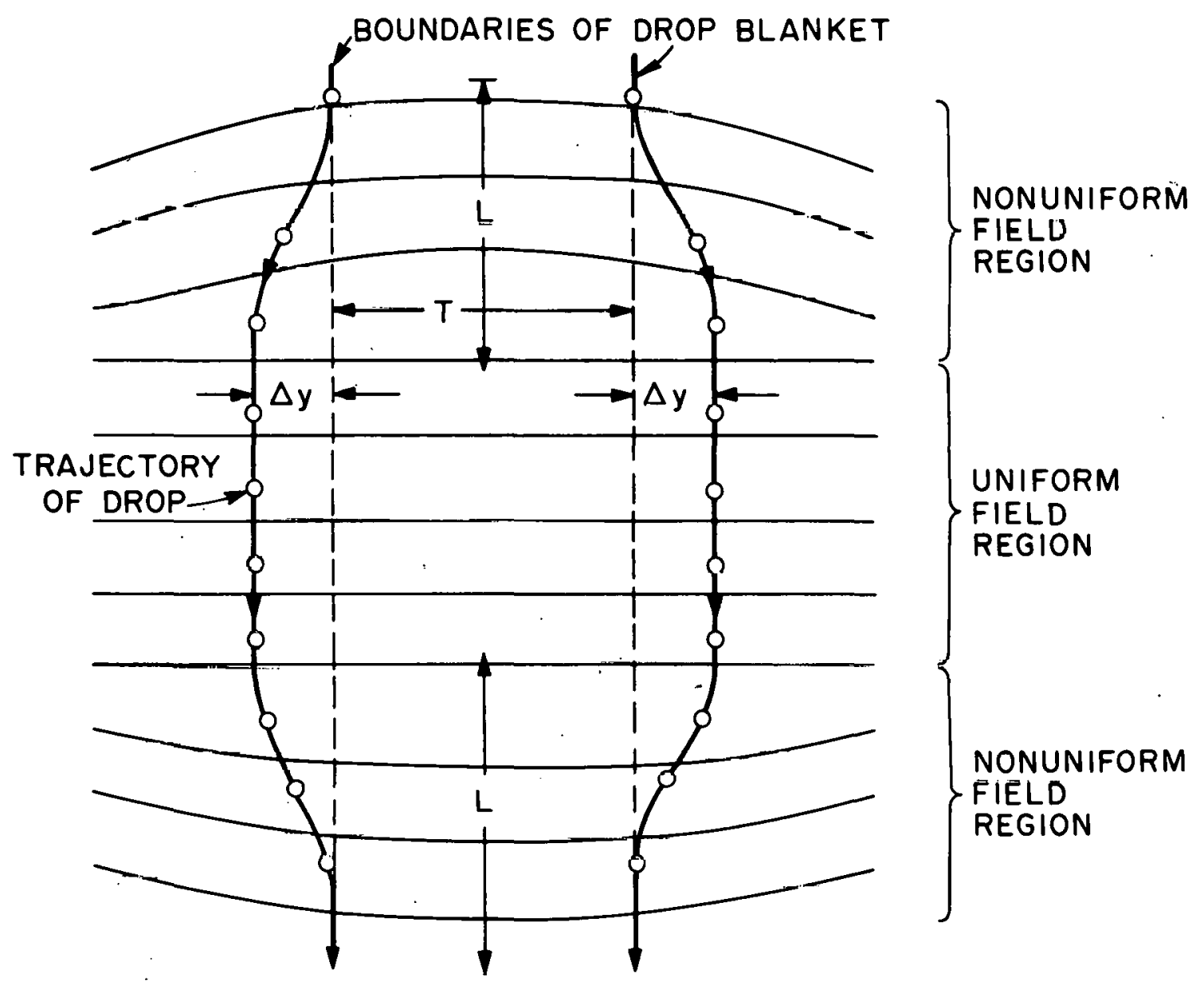

Fig. 13. Displacement of a drop as it moves through a region of uniform magnetic field. 


\section{REFERENCE}

1. W. M. Wells, ORNL TNS Progrom - Evaluation of the Bundle Divertor, ORNL/TM-6727, to be published. 
THIS PAGE.

\section{WAS INTENTIONALLY \\ LEFT BLANK}


ORNL/TM-6976

Dist. Category UC-20 d

INTERNAL DISTRIBUTION

1. W. R. Becraft

2. L. A. Berry

3. E. E. Bloom

4. T. G. Brown

5. J. D. Callen

6. D. D. Cannon

7. J. L. Dunlap

8. W. A. Houlberg

9. T. J. Huxford

10. M. S. Lubell

11. J. W. Lue

12. 0. B. Morgan

13. $\mathrm{Y}-\mathrm{K}$. M. Peng

14. R. L. Reid

15. M. W. Rosenthal

16. C. Sardella
17. J. L. Scott

18. T. E. Shannon

19. J. Sheffield

20. D. Steiner

21. J. S. Watson

22-32. W. M. Wel1s

33. G. W. Wiseman

34-35. Central Research Library

36-37. Fusion Energy Division

Library

38. Fusion Energy Division Communications Center

39-40. Laboratory Records Department

41. Laboratory Records, ORNL-RC

42. ORNL Patent office

43. Document Reference Section

\section{EXTERNAL DISTRIBUTION}

44. D. J. Anthony, General Electric Co., B1dg. 23, Rm. 290, 1 River Rd., Schenectady, NY 12.345

45. J. E. Baublitz, Office of Fusion Energy, Department of Energy, Washington, DC 20545

46. D. S. Beard, Office of Fusion Energy, Department of Energy, Washington, DC 20545

47. S. L. Bogart, Science Applications, Inc., 8400 Westpark Drive, McLean, VA 22102

48. R. Borw1n, Grumman Aeruspace Cuip., Bethpage, NY 11714

49. J. F. Clarke, Office of Fusion Energy, Department of Energy, Washington, DC 20545

50. F. E. Coffman, Office of Fusion Energy, Department of Energy, Washington, DC 20545

51. D. Cohn, Massachusetts Institute of Technology, Cambridge, MA 02139

52. Library, Culham Laboratory, Abingdon, Oxon, OX14 3DB, United Kingdom

53. H. W. Deckman, Advanced Energy Systems Laboratory, Government Research Laboratories, Exxon Research and Engineering Co., P.0. Box 8, Linden, NJ 07036

54. C. A. Flanagan, Westinghouse Electric Corp., Fusion Power Systems, P.0. Box 10864, Pittsburgh, PA 15236

55. H. K. Forsen, Exxon Nuclear Co., Inc., 777 106th Ave., Bellevue, WA 98009 
56. H. P. Furth, Princeton Plasma Physics Laboratory, Princeton University, P.0. Box 451, Princeton, NJ 08540

57. R. W. Gould, Mail Stop 116-81, California Institute of Technology, Pasadena, CA 91125

58. R. Hancox, Culham Laboratory, Abingdon, Oxon, 0X14 3DB, United Kingdom

59. C. R. Head, Office of Fusion Energy, Department of Energy, Washington, DC 20545

60. R. L. Hirsch, Exxon Research and Engineering Co., P.0. Box 101, Florham Park, NJ 07932

61. M. A. Hoffman, Lawrence Livermore Laboratory, P.0. Box 808, Livermore, CA 94550

62. Anthony Hsu, Office of Fusion Energy, Department of Energy, Washington, DC 20545

6]. D. L. Jassly, PLincelun Plasind Pliyslis Laburatury, Princeron University, P.O. Box 4S1, Princeton, NJ 08540

64. V. A. Maroni, Argonne National Laboratory, 9700 South Cass Ave., Ärgonne, $1 \mathrm{~L}$ bü43y

65. D. M. Meade, Princeton Plasma Physics Laboratory, Princeton University, P.0. Box 451, Princeton, NJ 08540

66. P. B. Mohr, Lawrence Livermore Laboratory, P.0. Box 808, Livermore, CA 94550

67. M. R. Murphy, Office of Fusion Energy, Department of Energy, Washington, DC 20545

68. J. M. Raw1s, General Atomic Co., P.0. Box 81608, San Diego, CA 92138

69. P. Reardon, Princeton Plasma Physics Laboratory, Princeton Univereity, P.0. Box 151, Princeton, NJ 08540

70. T. Reuther, Office of Fusion Energy, Department of Energy, Washington, DC 20545

71. M. Roberts, Office of Fusion Energy, Department of Energy, Washington, DC 20545

72. P. H. Sager, Jr., General Atomic Co., P.0. Box 81608, San Diego, CA 92138

73. G. Schilling, Princeton Plasma Physics Laboratory, Princeton University, P.0. Box 451, Princeton, NJ 08540

74. W. M. Stacey, Jr., School of Nuclear Engineering, Georgia Institute of Technology, Atlanta, GA 30332

75. F. Thomas, Grumman Aerospace Corp., Bethpage, NY 11714

76. T. C. Varljen, Westinghouse Electric Corp., Fusion Power Systems, P.0. Box 10864, Pittsburgh, PA 15236

77. S. S. Waddle, Department of Energy, Oak Ridge Operations, P.O. Box E, Oak Ridge, TN 37830

78-88. J. S. Walker, University of Illinois, Urbana, IL 61801

89. J. Willis, Office of Fusion Energy, Department of Energy, Washington, DC 20545

90. W. Wilkes, Mound Laboratories, Miamisburg, OH 45432

91. E. Ziurys, Office of Fusion Energy, Department of Energy, Washington, DC 20545

92. K. Zwilsky, Office of Fusion Energy, Department of Energy, Washington, DC 20545 
93. Office of Assistant Manager, Energy Research and Development, Department of Energy, Oak Ridge Operations, P.O. Box E, Oak Ridge, TN 37830

94-244. Given distribution as shown in TID-4500, Magnetic Fusion Energy (Distribution Category UC-20 d, Fusion Systems) 